\title{
Malignant mesothelioma in a cohort of asbestos insulation workers: clinical presentation, diagnosis, and causes of death
}

\author{
J RIBAK, RUTH LILIS, Y SUZUKI, L PENNER, I J SELIKOFF \\ From the Division of Environmental and Occupational Medicine, Department of Community Medicine, \\ Mount Sinai School of Medicine of the City University of New York, New York, NY 10029, USA
}

ABSTRACT Malignant mesothelioma has been rare in the general population. In recent decades its incidence has risen dramatically, parallel to the increasing use of asbestos in industry since 1930 . Altogether 17800 asbestos insulation workers, members of the International Association of Heat and Frost Insulators and Asbestos Workers (AFL-CIO-CLC) in the United States and Canada, were enrolled for prospective study on 1 January 1967 and followed up to the present. Every death that occurs is investigated by our laboratory. One hundred and seventy five deaths from mesothelioma occurred among the 2221 men who died in 1967-76 and 181 more such deaths in the next eight years. Altogether, 356 workers had died of malignant mesothelioma (pleural or peritoneal) by 1984 . Diagnosis of mesothelioma was accepted only after all available clinical, radiological, and pathological material was reviewed by our laboratory and histopathological confirmation by the pathology unit made in each case. One hundred and thirty four workers died of pleural and 222 of peritoneal mesothelioma. Age at onset of exposure, age at onset of the disease, and age at death were similar in both groups of patients. Significant difference was noted only in the time elapsed from onset of exposure to the development of first symptoms, which was longer in the group with peritoneal mesothelioma. Shortness of breath, either new or recently increased, and chest pain were the most frequent presenting symptoms in the group with pleural mesothelioma; abdominal pain and distension were frequent in the patients with peritoneal mesothelioma. Pleural effusion or ascites were found in most patients. The most effective approach to the diagnosis of malignant pleural mesothelioma in these cases was by open lung biopsy; exploratory laparotomy was best for diagnosing peritoneal mesothelioma. Patients with pleural mesothelioma died principally from pulmonary insufficiency whereas those with peritoneal mesothelioma succumbed after a period of pronounced wasting.

The existence of malignant mesothelioma as a primary tumour of the pleura or peritoneum was controversial for many years, reflecting the fact that primary tumours of serosal surfaces are relatively rare. As early as 1767 , Joseph Lieutand (cited by Robertson) reported two cases of probable pleural mesothelioma among 3000 necropsies. ${ }^{1}$ The pathology was first described by Wagner in $18700^{2}$ In 1854 Von Rokitansky described primary tumours of the peritoneum which he called "colloid cancer." ${ }^{3}$

The entity remained ill defined until Klemperer and

Accepted 26 January 1987
Rabin, in 1931, described the distinctive features of diffuse neoplasms of the pleura in detail and recommended that these tumours be called mesothelioma since they arise from the mesothelium. ${ }^{4}$ Godwin in 1957 proposed criteria for the diagnosis of pleural mesothelial tumours ${ }^{5}$ and Winslow and Taylor in 1960 did the same for peritoneal mesothelial tumours. ${ }^{6}$

Nevertheless, only during the past 25 years has malignant mesothelioma been widely accepted as an independent diagnostic entity. The first large series of diffuse malignant mesothelioma was reported in 1960 by Wagner et al from the North Western Cape province in South Africa. ${ }^{7}$ A total of 33 cases of pleural mesothelioma was described; almost all had worked 
with asbestos or had lived in close vicinity of asbestos mines and mills. By 1962 Wagner $e t$ al had diagnosed 89 cases of malignant mesothelioma ${ }^{8}$; two were peritoneal. In only two patients could a history of exposure to asbestos not be established.

In 1955 Bonser et al had found four cases of peritoneal mesothelioma among necropsies of 72 patients with asbestosis. ${ }^{9}$ Mancuso and Coulter, ${ }^{10}$ Hourihane, ${ }^{11}$ and Enticknap and Smither, ${ }^{12}$ reported increased numbers of mesothelioma found at necropsies of asbestos workers or other patients with asbestosis.

Population based epidemiological studies served firmly to establish the aetiological link between exposure to asbestos and mesothelioma. ${ }^{13}$ In a cohort study of asbestos insulation workers 10 cases of malignant mesothelioma (four pleural and six peritoneal) were found in 307 consecutive deaths.

The incidence of mesothelioma in general population necropsy series has been reported to vary between $0.01 \%$ and $0.07 \%$, with a definite male predominance. Since 1960 the incidence of the disease has risen continuously, subsequent to the ever increasing use of asbestos in industry (including construction work, shipbuilding, and repair) since 1930. During the second world war, employment in the United States shipyards rose from 168000 workers in 1940 to 1772000 in November 1943. The combination of large numbers of workers and high rate of labour turnover resulted in the employment of many people who were then exposed to asbestos, and a high incidence of cases of mesothelioma could therefore be expected in the following decades. ${ }^{14}$ The increase in the incidence of mesothelioma continues; useful data have recently been published. ${ }^{15}$

\section{Present study}

A large cohort of asbestos insulation workers (17800 men) has been followed up in the division of environmental and occupational medicine, Mount Sinai Medical Center, since 1967. The criteria for inclusion in the cohort, its characteristic features, and initial mortality experience have been previously reported. ${ }^{16}$

A total of 356 members of the cohort died of malignant mesothelioma (peritoneal and pleural) between 1967 and the end of 1984 . We report here clinical characteristics of these cases: the clinical presentation of the disease, the methods of diagnosis and their relative value, and the main direct (immediate) causes of death.

\section{Materials and methods}

On 1 January 1967 a large cohort of asbestos insulation workers was enrolled for prospective observation.
It was composed of all 17800 men on the rolls of the International Association of Heat and Frost Insulators and Asbestos Workers (AFL-CIO-CLC) in the United States and Canada on that day and included New York-New Jersey asbestos workers in whom a significant increase in deaths from lung cancer and mesothelioma had been originally detected. ${ }^{17}$

The United States-Canada cohort of asbestos insulation workers has been followed up to 1984 and observation continues. With the valuable help of the insulation workers union, every death that has occurred in the cohort has been reported to one of us (IJS). All pertinent information regarding every death (clinical records, $x$ ray films, necropsy reports, histopathological specimens, death certificates) was sought.

All information gathered was evaluated and a diagnosis of mesothelioma was accepted only after detailed pathological examination of surgical or postmortem material by our pathology unit (M Kannerstein, J Churg, Y Suzuki). The criteria used for the pathological diagnosis of mesothelioma have been published elsewhere. $^{18}$

By the end of 1976, 2221 deaths had occurred ${ }^{16}$; with continued observation, we were notified of about 3500 deaths by the end of 1984 . There were deaths recorded as being due to mesothelioma but in which confirmation on review of the pathological material was not achieved (YS). These were not accepted by us for this series; nor were cases of diffuse intrathoracic or abdominal neoplastic disease with a presumptive or clinical diagnosis of mesothelioma. We preferred to limit inclusion only to those cases where histopathological material was available, submitted to us for examination and study, and then verified as meeting the criteria for diagnosis of mesothelioma. According to such evidence, 356 cases of malignant mesothelioma have occurred since 1967 with 134 pleural and 222 peritoneal mesotheliomas among these 3500 deaths.

All available information was prepared on a standardised special form. Demographic data, duration (years) of asbestos exposure and time from onset of exposure, type of work, smoking history, and detailed clinical features of each case were recorded.

\section{Results}

A total of 356 cases of malignant mesothelioma was identified (134 pleural, 222 peritoneal).

Figure 1 displays the distribution of the age at death in cases of pleural and peritoneal mesothelioma. Figure 2 presents the distribution of years since onset of exposure in both groups. Table 1 compares age at onset of exposure, duration since onset of exposure, age at onset of disease, and age at death for cases of pleural and peritoneal mesothelioma. No statistically significant differences were found except for duration 


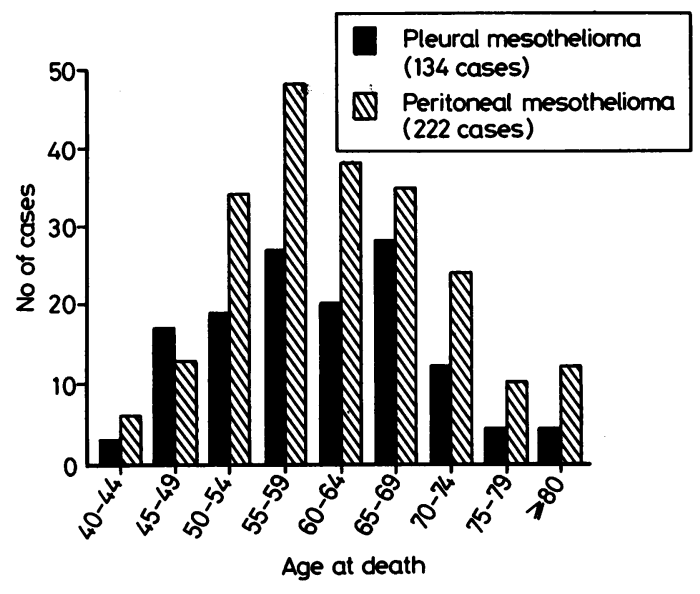

Fig 1 Age at death, comparison between pleural and peritoneal mesothelioma.

Table 1 Age and information on exposure to asbestos in 356 consecutive cases of mesothelioma

\begin{tabular}{lll}
\hline & $\begin{array}{l}\text { Pleural } \\
\text { Mean }(+S D)\end{array}$ & $\begin{array}{l}\text { Peritoneal } \\
\text { Mean }(+S D)\end{array}$ \\
\hline Age at onset of exposure & $25 \cdot 5$ & $24 \cdot 9$ \\
(years) & $(7 \cdot 2)$ & $(6 \cdot 9)$ \\
Duration since onset of exposure & $33 \cdot 8^{*}$ & $36 \cdot 4$ \\
(years) & $(8 \cdot 9)$ & $(9 \cdot 7)$ \\
Age at onset of disease & $59 \cdot 1$ & $60 \cdot 9$ \\
(years) & $(9 \cdot 4)$ & $(9 \cdot 6)$ \\
Age at death & $60 \cdot 1$ & $61 \cdot 4$ \\
(years) & & \\
\hline
\end{tabular}

${ }^{*} t$ test $\mathrm{p}=0.0125$.

since onset of exposure which tended to be longer for peritoneal cases $(t=2.51, p=0.01)$.

Smoking history showed that $45 \%$ of the cases were current smokers, $36 \%$ were previous smokers, and $19 \%$ had never smoked. The distribution was similar in both groups. Cigarette smoking has little or no

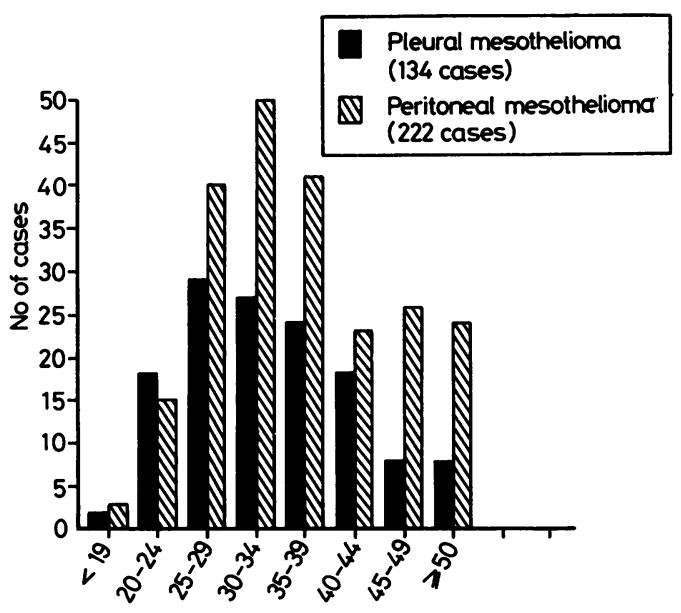

Years since onset of exposure

Fig 2 Years since onset of exposure, comparison between pleural and peritoneal mesothelioma.

effect on death rates from mesothelioma, unlike its influence on lung cancer. ${ }^{19}$

\section{CLINICAL PRESENTATION AND LABORATORY FINDINGS}

Table 2 displays the main presenting symptoms in the subgroups of pleural and peritoneal mesothelioma. In the pleural group recent onset or increase of shortness of breath and chest pain were the most frequent symptoms. Five cases were detected during routine chest $x$ ray examination while they were still asymptomatic. In the peritoneal group abdominal pain and distension accounted for $77 \%$ of the presenting symptoms. It is of interest that in eight cases the presenting symptom was interpreted as inguinal hernia. In seven cases bowel obstruction was an early symptom.

Table 3 summarises the frequency of symptoms and signs that were present at the onset of the disease. Pleural effusion was the main manifestation $(54 \%)$ in

Table 2 Main presenting symptoms and signs in 310 consecutive cases of mesothelioma among asbestos insulation workers 1967-84

\begin{tabular}{|c|c|c|c|c|c|}
\hline \multirow[b]{2}{*}{ Symptoms* } & \multicolumn{2}{|c|}{ Pleura (113) } & \multirow[b]{2}{*}{ Symptoms $\dagger$} & \multicolumn{2}{|c|}{ Peritoneal (197) } \\
\hline & $\overline{N o}$ & $\%$ & & $\overline{N o}$ & $\%$ \\
\hline $\begin{array}{l}\text { Recent onset of shortness of breath } \\
\text { Chest pain } \\
\text { Recent increase of shortness of breath } \\
\text { Pleural effusion }\end{array}$ & $\begin{array}{r}28 \\
25 \\
25 \\
7\end{array}$ & $\begin{array}{r}24 \cdot 8 \\
22 \cdot 1 \\
22 \cdot 1 \\
6 \cdot 2\end{array}$ & $\begin{array}{l}\text { Abdominal pain } \\
\text { Abdominal distension } \\
\text { Weight loss } \\
\text { Bowel obstruction }\end{array}$ & $\begin{array}{r}79 \\
73 \\
10 \\
7\end{array}$ & $\begin{array}{r}40 \cdot 0 \\
37 \cdot 0 \\
5 \cdot 0 \\
3 \cdot 6\end{array}$ \\
\hline $\begin{array}{l}\text { Asymptomatic abnormality on } \\
\text { routine chest } x \text { ray }\end{array}$ & 5 & $4 \cdot 4$ & $\begin{array}{l}\text { Abdominal mass } \\
\text { Ascites }\end{array}$ & $\begin{array}{l}4 \\
2\end{array}$ & $\begin{array}{l}2 \cdot 0 \\
1 \cdot 0\end{array}$ \\
\hline
\end{tabular}

*Weakness, chest tightness, weight loss, and bone pain were each the presenting symptom in less than $5 \%$ of cases.

†Inguinal hernia, weakness, fever, nausea, anorexia, obstructive uropathy: less than $5 \%$.

In 21 pleural cases and 25 peritoneal cases inadequate data on symptoms were available. 
Table 3 Symptoms and signs during the course of the disease in 310 consecutive cases of mesothelioma among asbestos insulation workers

\begin{tabular}{|c|c|c|c|c|c|}
\hline \multirow[b]{2}{*}{ Symptoms } & \multicolumn{2}{|c|}{ Pleura (113 cases) } & \multirow[b]{2}{*}{ Symptoms } & \multicolumn{2}{|c|}{ Peritoneal (197 cases) } \\
\hline & No & $\%$ & & No & $\%$ \\
\hline $\begin{array}{l}\text { Pleural effusion } \\
\text { Chest pain } \\
\text { Cough } \\
\text { Recent onset of shortness of breath } \\
\text { Recent increase of shortness of breath } \\
\text { Weight loss } \\
\text { Weakness } \\
\text { Increased sputum production }\end{array}$ & $\begin{array}{l}61 \\
49 \\
40 \\
35 \\
34 \\
26 \\
21 \\
20\end{array}$ & $\begin{array}{l}54 \cdot 0 \\
43 \cdot 4 \\
35 \cdot 4 \\
31 \cdot 0 \\
30 \cdot 0 \\
23 \cdot 0 \\
18 \cdot 6 \\
17 \cdot 7\end{array}$ & $\begin{array}{l}\text { Abdominal pain } \\
\text { Abdominal distension } \\
\text { Weight loss } \\
\text { Ascites } \\
\text { Anorexia } \\
\text { Weakness } \\
\text { Nausea } \\
\text { Abdominal mass }\end{array}$ & $\begin{array}{r}118 \\
111 \\
75 \\
72 \\
54 \\
23 \\
22 \\
21\end{array}$ & $\begin{array}{l}59 \cdot 9 \\
56 \cdot 4 \\
38 \cdot 1 \\
36 \cdot 5 \\
27 \cdot 4 \\
11 \cdot 7 \\
11 \cdot 2 \\
10 \cdot 7\end{array}$ \\
\hline
\end{tabular}

In 21 pleural cases and 25 peritoneal cases inadequate data on symptoms were available.

Table 4 Results of diagnostic procedures in cases of pleural mesothelioma

\begin{tabular}{|c|c|c|c|c|c|c|c|c|c|}
\hline & & $\begin{array}{l}\text { Positive } \\
\text { No }\end{array}$ & $\%$ & $\begin{array}{l}\text { Negative } \\
\text { No }\end{array}$ & $\%$ & $\begin{array}{l}\text { Equivocal } \\
\text { No }\end{array}$ & $\%$ & $\begin{array}{l}\text { Other } \\
\text { No }\end{array}$ & $\%$ \\
\hline $\begin{array}{l}\text { Thoracocentesis } \\
\text { Biopsy, needle } \\
\text { Biopsy, open } \\
\text { Surgery }\end{array}$ & $\begin{array}{l}(74) \\
(50) \\
(78) \\
(39)\end{array}$ & $\begin{array}{l}23 \\
31 \\
61 \\
36\end{array}$ & $\begin{array}{l}31 \cdot 0 \\
62 \cdot 0 \\
78 \cdot 2 \\
92 \cdot 3\end{array}$ & $\begin{array}{r}38 \\
10 \\
2 \\
1\end{array}$ & $\begin{array}{r}51 \cdot 4 \\
20 \cdot 0 \\
2 \cdot 6 \\
2 \cdot 6\end{array}$ & $\begin{array}{c}13 * \\
9 \\
3 \\
-\end{array}$ & $\begin{array}{r}17 \cdot 6 \\
8.0 \\
3.9 \\
\end{array}$ & $\frac{-}{12}$ & $\begin{array}{r}- \\
15 \cdot 4 \\
5 \cdot 1\end{array}$ \\
\hline
\end{tabular}

*"Carcinoma" reported.

Table 5 Results of diagnostic procedures in cases of peritoneal mesothelioma

\begin{tabular}{|c|c|c|c|c|c|c|c|c|c|}
\hline & & $\begin{array}{l}\text { Positive } \\
\text { No }\end{array}$ & $\%$ & $\begin{array}{l}\text { Negative } \\
\text { No }\end{array}$ & $\%$ & $\begin{array}{l}\text { Equivocal } \\
\text { No }\end{array}$ & $\%$ & $\begin{array}{l}\text { Other } \\
\text { No }\end{array}$ & $\%$ \\
\hline $\begin{array}{l}\text { Paracentesis } \\
\text { Surgery* }\end{array}$ & $\begin{array}{l}(108) \\
(201)\end{array}$ & $\begin{array}{r}27 \\
109\end{array}$ & $\begin{array}{l}24 \cdot 5 \\
54 \cdot 3\end{array}$ & 43 & $40 \cdot 0$ & $\begin{array}{r}38 \\
8\end{array}$ & $\begin{array}{r}35.4 \\
4.0\end{array}$ & $84 \dagger$ & 41.8 \\
\hline
\end{tabular}

*Exploratory laparotomy was performed in $75 \%$ of the cases.

†Other diagnosis offered were: adenocarcinoma, carcinomatosis primary unknown, metastatic undifferentiated carcinoma.

the group with pleural mesothelioma as was ascites in the group with peritoneal mesothelioma (36.5\%). Weight loss was more pronounced in peritoneal cases whereas fever accompanied more of the pleural cases.

\section{METHODS OF DIAGNOSIS}

In the group with pleural mesothelioma (table 4)

Table 6 Immediate cause of death in 356 consecutive cases of mesothelioma among asbestos insulation workers 1967-84

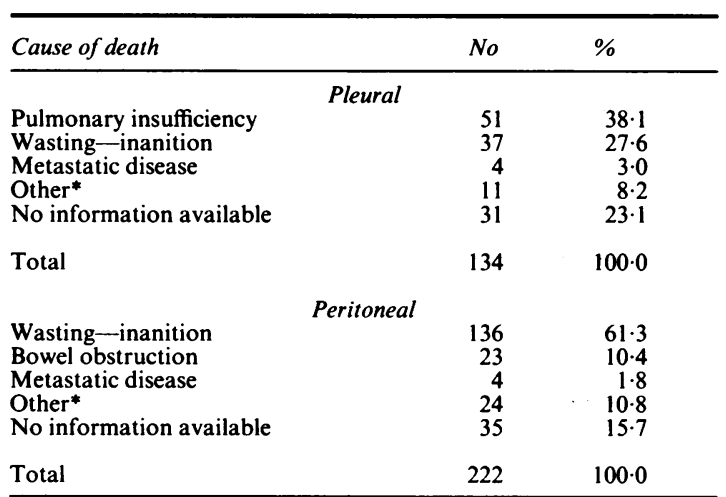

*Other causes included: cardiopulmonary arrest, stroke, car accidents. thoracocenteses were done in $74(55 \%)$. In most of these $(68 \%)$ the quantity of fluid was large (defined as more than $1500 \mathrm{cc}$ ) and in $25 \%$ it was medium (500$1500 \mathrm{cc}$ ). In $45 \%$ of the cases the pleural effusion was haemorrhagic. Pathological examination of the fluid yielded positive results in only $31 \%$ of the cases. In most the results tended to be non-diagnostic (52\%).

Biopsies were performed in 128 cases. Needle biopsy was done in 50 , yielding positive results in $62 \%$ of these. Open biopsy was performed in 78 cases; in 61 $(78.2 \%)$ it yielded positive results whereas in 10 $(13.5 \%)$ other diagnoses were made (including lung cancer, fibrosarcoma, and lymphoma).

Thirty nine patients underwent surgery; 19 had decortication, eight pneumonectomy, two lobectomy, and 10 other palliative procedures.

Bronchoscopy was done in 51 cases (29 with a rigid bronchoscope and 22 with a flexible fibre optic bronchoscope). As expected, this procedure did not contribute to diagnosis, except in two cases.

In the peritoneal group paracenthesis was done in 108 cases $(48.6 \%)$; in $75 \%$ of these the effusion was large (table 5). The fluid was mostly yellowish in colour $(68.3 \%)$; it was haemorrhagic in $22.8 \%$. The cytology evaluation yielded a positive diagnosis in only $24.5 \%$ of the 108 cases whereas it was non- 
diagnostic in $40 \%$ and other diagnoses were suggested in the rest.

Surgery had been performed in 201 of the peritoneal cases $(90.5 \%)$, mainly for diagnostic purposes. In 84 cases $(41.8 \%)$ diagnoses other than mesothelioma were suggested after surgery, as compared with only $13.5 \%$ in the pleural mesothelioma group. These findings highlight the difficulty of diagnosing mesothelioma in general and peritoneal mesothelioma in particular.

\section{IMMEDIATE CAUSES OF DEATH}

Immediate causes of death are presented in table 6 . In the group with pleural mesothelioma most of the cases $(38 \%)$ died of pulmonary insufficiency whereas most of the cases with peritoneal mesothelioma died of wasting and inanition $(61 \%)$. There were no significant differences between treated and untreated patients or smokers and non-smokers with regard to the immediate cause of death.

\section{Discussion}

Many studies on mesothelioma have been published; most do not start from a population basis and do not attempt to gather all possible clinical, radiological, and pathological information. Cases are usually collected from local hospitals, state services, chest clinics, pneumoconiosis boards, and registries. Thus they record only diagnosed cases of mesothelioma which in many cases leads to an underestimation of the true incidence $^{20}$ and may also include cases with other diseases misdiagnosed as mesothelioma.

Another difficulty in some studies, which causes problems in evaluating the relation of exposure to asbestos to mesothelioma, is that an exhaustive occupational and environmental history is not taken in many cases; information concerning exposure may be missed under such circumstances.

In this investigation we started with a large cohort of asbestos insulation workers that has been followed up prospectively. All clinical, radiological, and pathological information regarding each death has been sought and material provided and assessed. The strong relation between exposure to asbestos and mesothelioma is shown by the fact that almost $10 \%$ of the deaths in this cohort were due to mesothelioma whereas in the general population the proportion of cases of mesothelioma found at necropsy is small $(0.01 \%-0.07 \%)$.

In our series $60 \%$ of the cases were peritoneal mesothelioma whereas in most other reports on mesothelioma the ratio between pleural and peritoneal mesothelioma is the opposite, ${ }^{21-26}$ with many more cases of pleural than of peritoneal mesothelioma; however, in several studies our observation of a greater proportion of peritoneal to pleural was also reported. ${ }^{1227}$

One possible explanation might be that peritoneal mesothelioma is more frequently underdiagnosed than pleural mesothelioma. Since we used pathological evaluation and verification of postmortem material or surgical and biopsy specimens to ascertain the diagnosis, we could identify many cases of peritoneal mesothelioma that had been misdiagnosed as other causes of death (including cancers of the pancreas and colon and abdominal carcinomatatosis). ${ }^{16}$ Another possible explanation might stem from the fact that we are dealing with a specific group of insulation workers and the ratio of pleural mesothelioma to peritoneal mesothelioma could be different than in other series that investigate different occupational groups with different levels and patterns of exposure.

Duration since onset of exposure was similar in another study from the United States ${ }^{26}$ but shorter by ten years in a study in Canada ${ }^{23}$ The disease is rarely found in less than 15 years from onset of exposure.

Age at onset of the disease and age at death were similar in other studies. ${ }^{232428} 29$

Breathlessness and chest pain accompanied by pleural effusion were the main presenting symptoms in pleural mesothelioma. ${ }^{29-31}$ In peritoneal mesothelioma abdominal pain and ascites were the rule. It may be of value to mention some of the unusual presentations of mesothelioma in our series. Eight cases of peritoneal mesothelioma presented as hernia. This finding had been previously described. ${ }^{31}$ Some other unusual presentations of pleural mesothelioma have been noted elsewhere. A case presented as a superior vena cava syndrome; it later was found to be due to pleural mesothelioma. ${ }^{32} \mathrm{~A}$ case of pleural mesothelioma in the azygos fissure was also reported."

Pleural biopsy with thoracotomy was the most useful procedure for diagnosing pleural mesothelioma in this series, as in other reports. ${ }^{28-30} 33$ In peritoneal mesothelioma surgery (exploratory laparotomy) yielded the best diagnostic return, confirming observations of others. ${ }^{29} 30 \mathrm{~A}$ history of exposure to asbestos and the findings of tumour nodules of various sizes on the peritoneal, omental, and bowel serosa should be considered highly suspicious of malignant peritoneal mesothelioma. Still, pathological confirmation is absolutely necessary. In pleural mesothelioma the situation is somewhat better and the physician will more readily suspect neoplastic disease in an asbestos worker with history of cough, chest pain, recent weight loss, and pleural effusion.

Regarding the immediate cause of death in patients with mesothelioma, our observations agree with what has been found in other studies. ${ }^{22} 28$ Patients with pleural mesothelioma died mostly from pulmonary insufficiency whereas patients with peritoneal meso- 
thelioma died most frequently from wasting and inanition with spread of the disease in the abdominal cavity and beyond.

Dr Ribak's present address is Department of Preventive and Social Medicine, Tel-Aviv University, Sackler School of Medicine, Ramat Aviv, Tel-Aviv, Israel.

\section{References}

1 Robertson HE. Endothelia of the pleura. J Cancer Res 1924;8: 317.

2 Wagner E. Das tuberkelahnliche Lymphadenom. Arch Heilk 1870;11:497.

3 Rokitanski C. Manual of pathological anatomy. London: Sydenam Society Transactions 1854:265.

4 Klemperer P, Rabin CB. Primary neoplasms of the pleura (a report of five cases). Archives of Pathology 1931;141:385-412.

5 Godwin MC. Diffuse mesotheliomas with comment on their relation to localized fibrous mesotheliomas. Cancer 1957;10: 298-319.

6 Winslow DJ, Taylor HB. Malignant peritoneal mesotheliomas. Cancer 1960;13:127-36.

7 Wagner JC, Slegges CA, Marchand P. Diffuse pleural mesothelioma and asbestos exposure in the North Western Cape Province. Br J Ind Med 1960;17:260-71.

8 Wagner JC. Epidemiology of diffuse mesothelial tumors: evidence of an association from studies in South Africa and United Kingdom. Ann NY Acad Sci 1965;132:575-8.

9 Bonser GM, Faulds JS, Stewart MJ. Occupational cancer of urinary bladder in dyestuffs operatives and of lung cancer in asbestos textile workers and iron ore miners. Am J Clin Pathol 1955;25:126-34.

10 Mancuso TF, Coulter EJ. Methodology in industrial health studies. Arch Environ Health 1963;6:210-26.

11 Hourihane DO. The pathology of mesotheliomata and analysis of their association with asbestos exposure. Thorax 1964;19: 268-78.

12 Enticknap JB, Smither WPJ. Peritoneal tumours in asbestosis. Br J Ind Med 1964;21:20-31.

13 Selikoff IJS, Churg J, Hammond EC. Relations between exposure to asbestos and mesothelioma. $N$ Engl J Med 1965;272:560-5.

14 Nicholson WJ, Perkel G, Selikoff IJS. Occupational exposure to asbestos: population at risk and projected mortality-19802030. Am J Ind Med 1982;3:259-311.

15 Spirtas R, Beebe GW, Connelly RR, et al. Recent trends in mesothelioma incidence in the United States. Am J Ind Med 1986;9:397-407.

16 Selikoff IJS, Hammond EC, Seidman H. Mortality experience of insulation workers in the United States and Canada, 1943-1976. Ann NY Acad Sci 1979;330:91-116.

17 Selikoff IJS, Churg J, Hammond EC. Asbestos exposure and neoplasia. JAMA 1964;188:22-6.

18 Suzuki Y. Pathology of human malignant mesothelioma. Semin Oncol 1981;8:268-82.

19 Hammond EC, Selikoff IJS, Seidman H. Asbestos exposure, cigarette smoking and death rates. Ann NY Acad Sci 1979;330: 473-90.

20 Lilienfeld DE, Gunderson PD. Malignant mesothelioma as a cause of death in Minnesota: a medical-epidemiologic dilemma. Minnesota Medicine 1986;69:23-5.

21 Armstrong BK, Musk AW, Baker JE, Hunt JM, Newall CC, Henzel HR. Epidemiology of malignant mesothelioma in Western Australia. Med J Aust 1984;141:86-8.

22 Vogelzang NJ, Schultz SM, Iannucci AM, Kennedy BJ. Malignant mesothelioma-the University of Minnesota experience. Cancer 1984;53:377-83.

23 Finkelstein MM. Mortality among employees of an Ontario asbestos cement factory. Am Rev Respir Dis 1984;129:754-61.

24 Baba K. Indications of an increase of occupational pleural mesothelioma in Japan. J UOEH 1983;5:3-15.

25 Churg J. Malignant mesothelioma in British Columbia in 1982. Cancer 1985;55:672-4.

26 Wright WE, Sherwin RP, Dickson EA, Bernstein L, Fromm JB, Henderson BE. Malignant mesothelioma: incidence, asbestos exposure and reclassification of histopathology. $\mathrm{Br} \mathrm{J}$ Ind Med 1984;41:39-45.

27 Newhouse ML, Berry G. Patterns of mortality in asbestos factory workers in London. Ann NY Acad Sci 1979;330:53-60.

28 Dorward AJ, Stack BH. Diffuse malignant pleural mesothelioma in Glasgow. Br J Dis Chest 1981;75:397-402.

29 Elmes PC. The natural history of mesothelioma of the pleura. $J$ Coll Phys Surg 1972;1:117-23.

30 Borow M, Conston A, Livornese LL, Schalet N. Mesothelioma and its association with asbestos. JAMA 1967;201:587-91.

31 Brenner J, Sordillo PP, Magill GB. An unusual presentation of malignant mesothelioma: the incidental finding of tumour in the hernia sac during herniorrhaphy. J Surg Oncol 1981;18:159-61.

32 Ragalie GF, Varkey B, Chou H. Malignant pleural mesothelioma presenting as superior vena cava syndrome. Can Med Ass J 1983;128:689-91.

33 Martensson G, Hagmar B, Zettergren L. Diagnosis and prognosis in malignant pleural mesothelioma. A prospective study. Eur J Respir Dis 1984;65:169-78. 